\title{
Congenital Anterior Urethrocutaneous Fistula: A Case Report
}

\author{
Keywords: Urethra - Fistula - Congenital
}

Submitted: 17 October 2017; Accepted: 26 October 2017; Published online: 30 October 2017

\section{Introduction}

Congenital anterior urethrocutaneous fistula (CAUF), is a uncommon anomaly characterised by fistulisation of penile urethra to skin. It's usually seen as an isolated deformity or may accompany genitourinary or anorectal malformations [1,2]. The cause is obscure, but probably reflects a focal defect in the urethral plate that prevents fusion of the urethral folds [3-5].

\section{Case Report}

A 6-year-old boy presented with a fistula located on ventral penile urethra since birth. $\mathrm{He}$ was passing urine mostly through the external urethral meatus and also from this fistula. He was the only child born out of nonconsanguinous marriage. The antenatal period was uneventful. There was no history of trauma or surgical intervention. On examination, a $4 \times$ $3 \mathrm{~mm}$ fistula was noted at the subcoronal level (Figure 1). The urethra distal to the fistula was normal with intact prepuce and glan with mild chordee and left undescended testicle (Figure 2). The external urethral meatus was situated normally at the tip. The stretched penile length and diameter were normal for his age. The boy was operated under general anesthesia and fistula was identified at the level of subcoronal (Figure 3). It was calibrated with $8 \mathrm{Fr}$ catheter passing down to the urinary bladder easily. The fistula was repaired with local tissue flap and

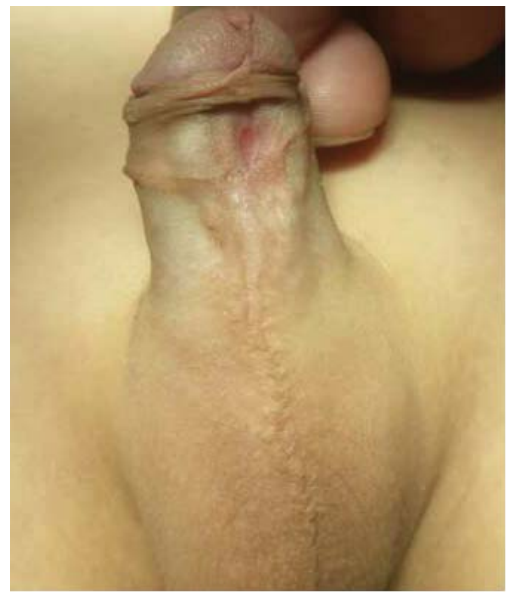

Figure 1: congenital uretrocutaneous fistula of our patient.

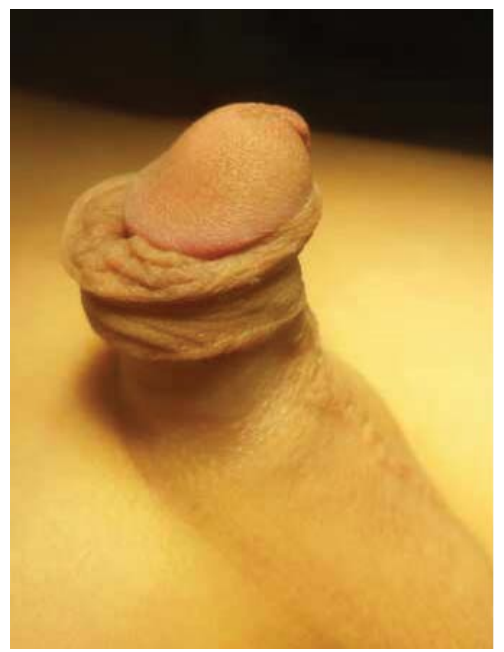

Figure 2: congenital uretrocutaneous fistula of our patient with mild chordee.
Changkai Deng ${ }^{1 *}$, Qiang Peng1, Xianliang $\mathrm{Hu}^{1}$, Yang $\mathrm{Lin}^{1}$, Fulin $\mathrm{Li}^{1}$, Chao Ma', Feng Liu²

'Department of Pediatric Surgery, Chengdu Women's and Children's Central Hospital of Chongqing Medical University, China

${ }^{2}$ Department of Urology Surgery, Children's Hospital of Chongqing Medical University, China

*Author for correspondence: 15882420198@163.com 


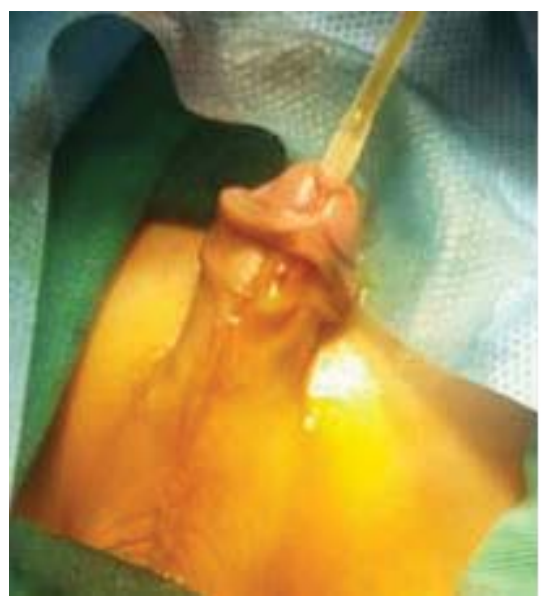

Figure 3: Perioperative image of congenital uretrocutaneous fistula of our patient with external urethral meatus being catheterized.

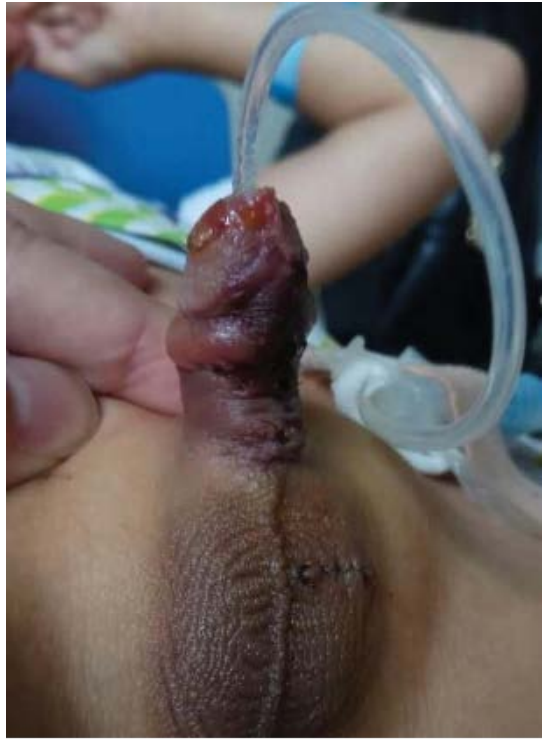

Figure 4: Postoperative image of congenital uretrocutaneous fistula of our patient with external urethral meatus being catheterized, 9th post-operative day.
Dartos fascia and skin were closed over it. The catheter was removed on 9 th post-operative day (Figure 4). Fistula recurred in this patient but resolved spontaneously after dilatations for 10 times within 3 months.

\section{Discussion}

The etiology of CAUF is still obscure and several pathogenetic theories have been used to explain its causes. Olbourne suggested that fistulae located in the penile shaft probably reflect a focal or temporary defect in urethral plate function and this would result in a complete defect or a partial deficiency of urethral fold fusion [5]. Goldstein theorized that a transient deficiency in testicular evocator substance could produce congenital urethral fistula with chordee [6].

63 patients in 34 articles were reported since 1962 [7]. We present 1 new case of CAUF. Locations of fistula were subcoronal in our patient. These are also the most common locations in the reports $[2,8]$. Subcoronal fistula was detected in 29 , midpenile in 24 , proximal penile to subcoronal level in 4 and penoscrotal in 1 . Included our patient, 9 patients with chordee and 20 with associated genitourinary anomalies were reported up to date with CAUF cases. The management of CAUF depends on size and location with all the principles of hypospadias surgery and repair should be individualized to the defect [8]. Our patient is belonged to small fistula and 3-layer closure with local tissue flap was performed. Fistula recurred in this patient but resolved spontaneously after dilatations for 10 times within 3 months.

\section{Conclusion}

CAUF is mainly located in subcoronal level and treatment of this entity is personalized according to size and locatiton of fistula. Success rates are high with the principles of hypospadias surgery.

\section{Executive summary}

Congenital anterior urethrocutaneous fistula (CAUF), is a uncommon anomaly characterised by fistulisation of penile urethra to skin. It's usually seen as an isolated deformity or may accompany genitourinary or anorectal malformations. The cause is obscure, but probably reflects a focal defect in the urethral plate that prevents fusion of the urethral folds. This case reports states that CAUF is mainly located in subcoronal level and treatment of this entity is personalized according to size and locatiton of fistula. Success rates are high with the principles of hypospadias surgery

\section{References}

1. Gupta, AK, Kumar M, Singh, K, et al. Rare association of congenital penile urethrocutaneous fistula with Y-type urethral duplication. BMJ Case Rep. (2017).

2. User, IR, Karakus, SC, Akcaer, V, et al. Congenital anterior urethrocutaneous fistula: 3 new cases and review of literature. Arch Esp Urol. 69(5): 238-243 (2016).
3. Karnak, I, Tanyel, FC, Hicsonmez, A. Congenital urethrocutaneous fistula: a case report and literature review, with a nomenclature proposal. J Pediatr Surg. 30(10): 15041505(1995).

4. Ritchey, ML, Sinha, A, Argueso, L. Congenital fistula of the penile urethra. J Urol. 151(4): 1061-1062 (1994).

5. Olbourne, NA. Congenital urethral fistula. Case reports. Plast Reconstr Surg. 57(2): 237-239 (1976). 
6. Goldstein, M. Congenital urethral fistula with chordee. J Urol. 113(1): 138-140 (1975).

7. Gupta, SC. An unusual type of hypospadias. Br J Plast Surg. 15(2): 191 (1962).
8. Alhazmi, HH. Congenital anterior urethrocutaneous fistula: Two case reports and review of literature. Urol Ann. 6(3):239241 (2014). 